\title{
The 1957 Great Aleutian Earthquake
}

\author{
Jean M. Johnson, ${ }^{1}$ Yuichiro Tanioka, ${ }^{1}$ Larry J. Ruff, ${ }^{1}$ Kenji Satake, ${ }^{1}$ \\ HIROO KANAMORI ${ }^{2}$ and LYNN R. SYKES ${ }^{3}$
}

\begin{abstract}
The 9 March 1957 Aleutian earthquake has been estimated as the third largest earthquake this century and has the longest aftershock zone of any earthquake ever recorded $-1200 \mathrm{~km}$. However, due to a lack of high-quality seismic data, the actual source parameters for this earthquake have been poorly determined. We have examined all the available waveform data to determine the seismic moment, rupture area, and slip distribution. These data include body, surface and tsunami waves. Using body waves, we have estimated the duration of significant moment release as $4 \mathrm{~min}$. From surface wave analysis, we have determined that significant moment release occurred only in the western half of the aftershock zone and that the best estimate for the seismic moment is $50-100 \times 10^{20} \mathrm{Nm}$. Using the tsunami waveforms, we estimated the source area of the 1957 tsunami by backward propagation. The tsunami source area is smaller than the aftershock zone and is about $850 \mathrm{~km}$ long. This does not include the Unalaska Island area in the eastern end of the aftershock zone, making this area a possible seismic gap and a possible site of a future large or great earthquake. We also inverted the tsunami waveforms for the slip distribution. Slip on the 1957 rupture zone was highest in the western half near the epicenter. Little slip occurred in the eastern half. The moment is estimated as $88 \times 10^{20} \mathrm{Nm}$, or $M_{w}=8.6$, making it the seventh largest earthquake during the period 1900 to 1993 . We also compare the 1957 earthquake to the 1986 Andreanof Islands earthquake, which occurred within a segment of the 1957 rupture area. The 1986 earthquake represents a rerupturing of the major 1957 asperity.
\end{abstract}

Key words: Subduction zones, Aleutian Arc, tsunamis, earthquake parameters.

\section{Introduction}

The Alaska-Aleutian Arc has a history of repeatedly rupturing in great earthquakes. The most recent sequence, beginning in 1938, has ruptured almost the entire arc from southern Alaska to the western Aleutians (Figure 1). Three earthquakes in particular, the 1957 Aleutian, 1964 Alaskan, and 1965 Rat Islands earthquakes are among the largest earthquakes to occur in the 20th century. However, some segments of the arc have apparently not ruptured during this

\footnotetext{
${ }^{1}$ Department of Geological Sciences, University of Michigan, Ann Arbor, Michigan, U.S.A.

${ }^{2}$ Seismological Laboratory, California Institute of Technology, Pasadena, California, U.S.A.

${ }^{3}$ Lamont-Doherty Earth Observatory, Department of Geological Sciences, Columbia University, Palisades, New York, U.S.A.
} 


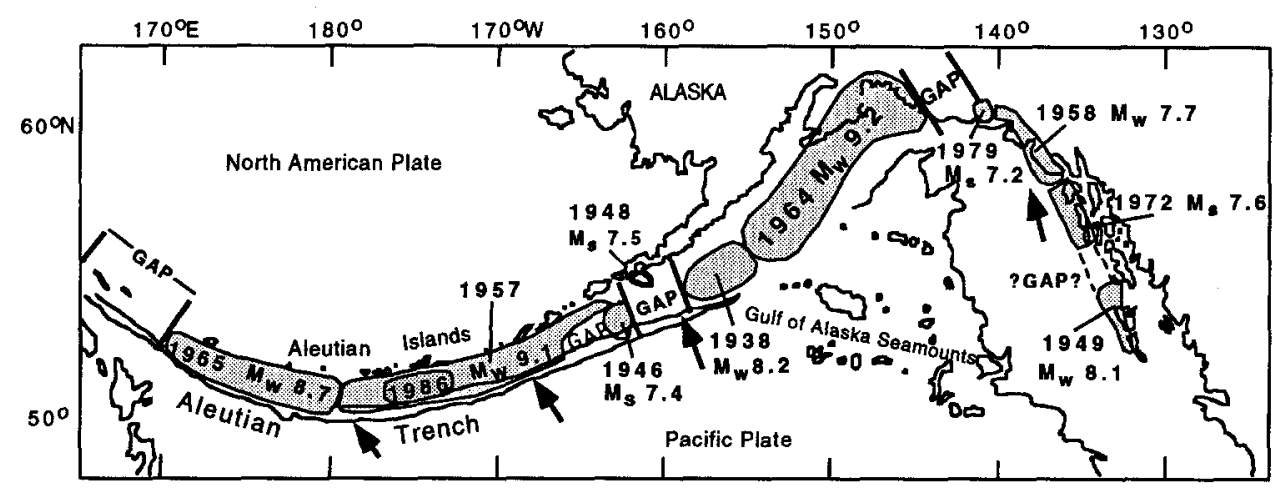

Figure 1

Locations of aftershock zones of major earthquakes and previously identified seismic gaps in Alaska and the Aleutians. Arrows indicate direction of relative convergence. Modified from SYKES et al. (1981).

sequence, and these areas are called seismic gaps. These gaps are delineated by the ends of the rupture zones of the adjacent great earthquakes; therefore, it is important to know the bounds of rupture of the great events. Of the three large events, both the 1964 and 1965 earthquakes occurred during the modern instrumental age of seismology, so they have been previously studied and their source parameters are known. However, the 9 March 1957 Aleutian earthquake (epicenter $51.63^{\circ} \mathrm{N}, 175.41^{\circ} \mathrm{W}$, at $14: 22 \mathrm{GMT}, M_{s}=8.1$ ) has been least understood because it occurred before the introduction of the WWSSN stations, and little seismic data are available. Elementary source parameters such as source area, seismic moment and slip distribution have been inadequately determined.

The source area of an earthquake is often identified as the region containing the aftershocks. The aftershock zone of the 1957 earthquake is the longest of any earthquake ever recorded. It stretches $1200 \mathrm{~km}$ along the Aleutian Trench from approximately $163.5^{\circ} \mathrm{W}$ to $180^{\circ} \mathrm{W}$, extending $360 \mathrm{~km}$ west and $850 \mathrm{~km}$ east of the epicenter. Both SYKes (1971) and KANAMORI (1977) used the $1200 \mathrm{~km}$ long aftershock zone of the 1957 earthquake in estimating the seismic moment. But these estimates are more than an order of magnitude different. Sykes' estimate of $30 \times 10^{20} \mathrm{Nm}$ is derived from the length of the aftershock zone and an average slip on the fault of $0.45 \mathrm{~m}$. Kanamori estimated the moment as $585 \times 10^{20} \mathrm{Nm}$, based on the relationship between source area and moment release, making the 1957 earthquake the third largest this century. However, House et al. (1981) argued that the easternmost end of the aftershock zone near Unalaska Island is anomalous and suggested that this area did not rupture in the 1957 earthquake.

An earthquake occurred on 7 May 1986 in the Andreanof Islands region $\left(M_{s}=7.7\right)$ within the rupture zone of the 1957 earthquake. This earthquake is important for several reasons. First, it was the largest earthquake to occur in this 
area of the Aleutians since the 1957 earthquake. Second, the epicenter of the 1986 earthquake $\left(51.41^{\circ} \mathrm{N}, 174.83^{\circ} \mathrm{W}\right)$ is very close to the epicenter of the 1957 earthquake. Third, this area had previously been thought to have "the lowest seismic potential for the next few decades" (NISHENKo and MCCANN, 1981) due to the occurrence of the 1957 event less than 30 years earlier. In this sense, the 1986 earthquake is a failure of the seismic gap hypothesis, and it is important to understand why. The 1986 earthquake could be related to the 1957 earthquake, filling in areas of low moment release of the 1957 event. Alternatively, the 1986 earthquake could represent a major rerupturing of the arc, marking the end of a complete seismic cycle and the beginning of a new interseismic period. If we are to resolve this question and correctly assess the seismic potential for the central Aleutian Arc, it is even more important to determine the moment release distribution of the 1957 earthquake.

In this paper, we will examine the seismic data, both body waves and surface waves, to determine what information can be derived from the limited data available. We will also examine the tsunami waveform data and how they can be used to give reliable estimates of the earthquake source parameters. This will allow us to determine if the Unalaska Island area is a seismic gap.

\section{Seismic Wave Studies}

We will first examine the body wave data, which will be used to view the rupture process. If the $1200 \mathrm{~km}$ long aftershock area represents the rupture area, typical rupture velocities predict that the source time function could be up to eight minutes long. Then we will examine the surface wave data. For such great earthquakes, long period surface waves provide better estimates of overall seismic moment because of the long wavelength.

\subsection{Body Waves}

The great difficulty in determining the source parameters for the 1957 earthquake is the dearth of high-quality seismic data. Fortunately, several IGY seismograms are available, but only four long period $P$ waves could be digitized from these. Of these four, Perth, Australia (PER) is at an epicentral distance of $103^{\circ}$; thus, the diffracted $P$ wave provides a four-minute window for the rupture process before the $P P$ arrival. Figure 2 shows the seismograms from PER for the main shock and one aftershock (occurred 9 March 1957, origin time 20:39 G.M.T., $M_{s}=7.1$ ). The duration of significant moment release appears to last only about 4 min, as the $P$-wave coda has decayed significantly.at the time of the $P P$ arrival. It is certainly possible that the $P$ wave continues after 4 min and is masked by the $P P$ arrival, but there is no indication of any arrival within the $P P$ coda that is larger 


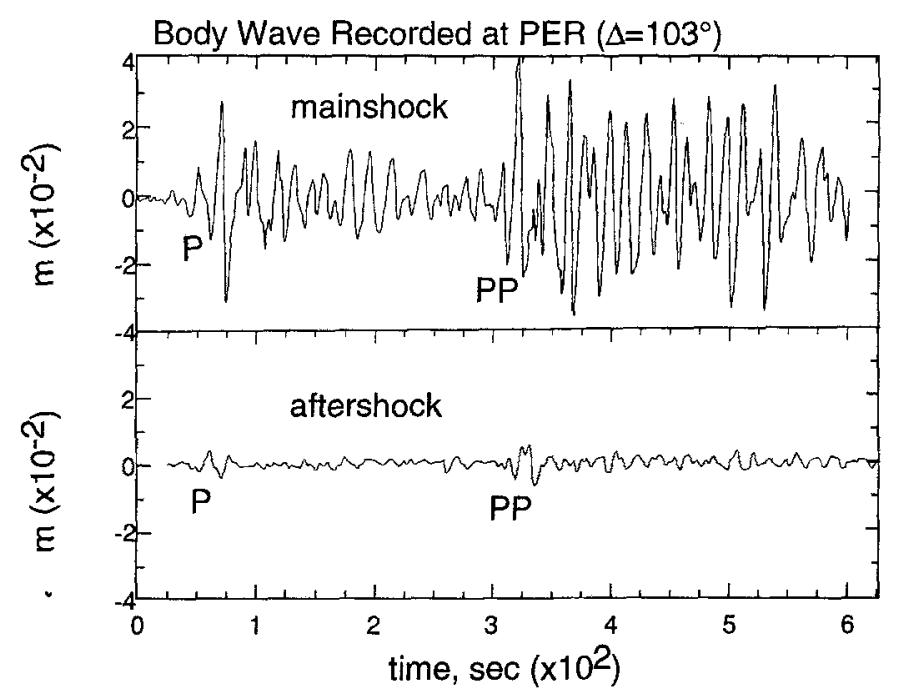

Figure 2

Seismograms of 1957 Aleutian earthquake (upper) and the large aftershock (lower) recorded at Perth, Australia (PER) showing $P$ and $P P$ arrival.

than the largest pulse that occurs about 1 min after the start of the record. Thus, there is no evidence to indicate significant moment release for longer than $4 \mathrm{~min}$, though there could be minor moment release for up to $8 \mathrm{~min}$. In a qualitative sense, the character of the $P$ wave does not suggest an earthquake of a magnitude as large as $M_{w}=9.1$, as compared to the body waves of the 1964 Alaska earthquake, $M_{w}=9.2$, in which the amplitude continues to grow for more than a minute after the first arrival (RUFF and KANAMORI, 1983).

If we assume that the duration of significant moment release is 4 min, we can approximate the along-strike length of the main rupture. Using rupture velocities of $1.5 \mathrm{~km} / \mathrm{s}$ and $3.0 \mathrm{~km} / \mathrm{s}$ as lower and upper limits of rupture velocity, the rupture length from the epicenter is $360 \mathrm{~km}$ and $720 \mathrm{~km}$, respectively. Either value is great enough to reach the western end of the aftershock zone. To the east, neither the lower nor the upper rupture length reaches to the eastern end of the aftershock zone. Without knowing anything more about the rupture velocity, we can say that a 4 min source duration is incompatible with a uniform rupture process across the entire aftershock zone.

We deconvolved each body wave record to estimate the single station source time function (RUFF and KANAMORI, 1983), each of which is shown in Figure 3. The PER source time function shows the 4 min duration. For the other three of the four source time functions, the $P P$ phase arrives before $4 \mathrm{~min}$. The magnification of the PER instrument is poorly known, but if we assume that the nominal instrument description for PER is correct (magnification of 1000), then the moment determined 


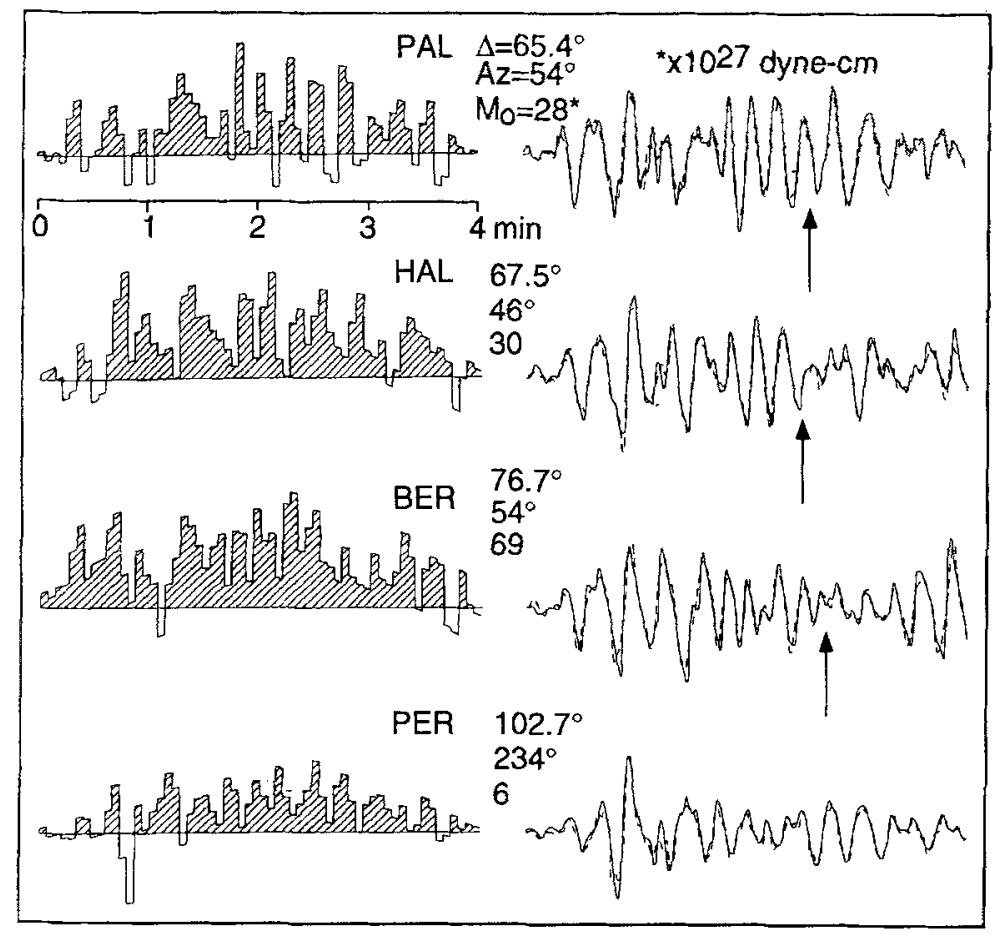

Figure 3

All available $P$ wave records (right) and the deconvolved source time functions (left) for the 1957 earthquake. Arrow heads indicate $P P$ arrival.

from the PER source time function is only $6 \times 10^{20} \mathrm{Nm}$. A better moment estimate can be obtained by use of the aftershock $P$ wave as an empirical Green's function. This gives the moment ratio of the main shock to the aftershock. The moment of the aftershock is estimated as $1 \times 10^{20} \mathrm{Nm}$, based on its magnitude. This yields a seismic moment between 20 and $80 \times 10^{20} \mathrm{Nm}$ for the main shock. As IGY instruments have poor long-period response compared to the long source duration (see RUFF and KANAMORI, 1983), the above body wave moment estimates provide a lower bound on seismic moment; thus, seismic moment can be arbitrarily large if the baseline is adjusted to include the large negative pulse at approximately 1 minute. Once again, in a qualitative sense, the 1957 source time function, with a number of small subevents in the first minute, is very different in character to a truly great event such as the 1964 Great Alaskan earthquake, whose source time function is ramping during the first minute (RUFF and KANAMORI, 1983). Interpreting this within the context of the asperity model, we can argue that the plate interface in the central Aleutians is fundamentally different in character than in southern Alaska, the former being made up of many small asperities, the latter having one large asperity. 
We can compare the source time function of the 1957 earthquake to the source time function of the 1986 earthquake (Figure 4). The two source time functions are similar during the first minute of rupture. Both build slowly via a number of pulses to the largest pulse of moment release, which can be clearly seen as the largest amplitude arrival in the seismograms. This again suggests that the central Aleutian plate interface is made up of a number of small asperities. Also, the 1957 and 1986 earthquakes are more complex than most subduction zone earthquakes in that each ruptured bilaterally from the epicenter (HWANG and KANAMORI, 1986; BOYD and NÁbÊleK, 1988; Houston and ENGdAhl, 1989; DAs and Kostrov, 1990; YOSHIDA, 1992).

\subsection{Surface Waves}

Several surface waveforms are also available; however, only one is at a nonnodal azimuth-Pietermaritzburg, South Africa (PTM). This record contains on-scale R3 and R4 waveforms which could be used for surface wave analysis. Unfortunately, the PTM instrument response is poorly known. The instrument galvanometer was repaired by the station operator, and the recalibrated instrument response was different from the nominal characteristics recorded on the seismogram. Despite this problem with the PTM record, it can be used to determine an estimate of the 1957 earthquake source parameters.

\section{A. Previous Studies}

LANE and BOYD (1990) used a nonlinear inversion (simulated annealing) to study the PTM record. This approach does not require that the instrument response be known, but they could estimate only the rupture length and velocity of the

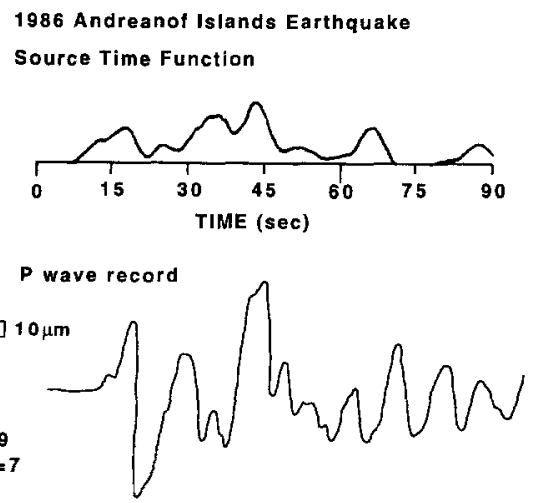

Figure 4

(Upper) Source time function of the 1986 Andreanof Islands earthquake (from HwaNG and KANAMORI, 1986). (Lower) Broadband $P$-wave displacement waveform for the 1986 Andreanof Islands earthquake recorded at Toledo, Spain (TOL). 
earthquake. They found that rupture extended approximately $600 \mathrm{~km}$ to the east and $150 \mathrm{~km}$ to the west of the epicenter, with a rupture velocity of $2.9 \mathrm{~km} / \mathrm{s}$.

Preliminary work to determine the slip distribution was done by RUFF et al. (1985). They determined the magnification of the PTM instrument by an empirical calibration at periods around $200 \mathrm{~s}$, using the estimated moment of the 1958 Kurile Islands earthquake. In detail, they matched the amplitude of the long period R3 pulse at PTM with a synthetic seismogram calculated for the model of FUKAO and FURUMOTO (1979). The found that, with seismometer and galvanometer periods of 15 and $59 \mathrm{~s}$ and damping parameters of 3 and 1 respectively, the apparent magnification of the PTM instrument was 114. Ruff et al. then matched the observed seismogram by inverting for nine point sources, each spatially separated by approximately $110 \mathrm{~km}$, as shown in Figure $5 \mathrm{a}$. The results of a linear inversion for the moment distribution with rupture velocity fixed at $1.6 \mathrm{~km} / \mathrm{s}$ (Figure $5 \mathrm{~b}$ ) show that the greatest moment release occurred in the western half of the aftershock zone, with no moment release in the eastern half. The seismic moment estimate from these results is $100 \times 10^{20} \mathrm{Nm}$.

The preliminary results of Ruff et al. are adequate to explain the long period aspects of the observed surface wave record; however, we wish to improve upon these results in several ways. First, Ruff et al. used only fundamental modes in creating the synthetic waveform. We wish to match the complexity of the observed waveform by including all modes down to a shorter period. Second, the previous results were for a homogeneous earth structure. Work of ZHANG and TANIMOTO (1993) has shown that there are significant lateral heterogeneities that can be corrected for in the surface wave velocities (Figure 6). These corrections can produce significant time shifts in our synthetic waveforms. Third, we wish to find the optimum rupture velocity. Ruff et al. fixed the rupture velocity at $1.6 \mathrm{~km} / \mathrm{s}$. We also attempted to determine an empirical Green's function for the 1957 earthquake by using the 1986 Andreanof Islands earthquake as a source; however, to our dismay, we found that no usable records are available from anywhere in Africa for the 1986 event, unfortunately closing that avenue of investigation.

\section{B. Surface Wave Inversion}

We construct Green's functions for the R3-R4 arrivals at PTM by the following method. We set up eleven subevents, each separated by approximately $100 \mathrm{~km}$, situated along the 1957 aftershock zone. The location and focal mechanism of each subevent is specified (see Figure 7). Details can be found below in the section on tsunami waveform inversion. The start time of each subevent is delayed by the prescribed rupture velocity. Synthetic waveforms are generated for each subevent by adding both fundamental and higher modes down to periods of $45 \mathrm{~s}$, using the earth model 1066A (GILBERT and DZIEwONSKI, 1975). The observed and synthetic waveforms are filtered using a low-pass Butterworth filter such that the amplitudes are $50 \%$ at a period of $150 \mathrm{~s}$ and $1 \%$ at a period of $45 \mathrm{~s}$, with respect to the values 


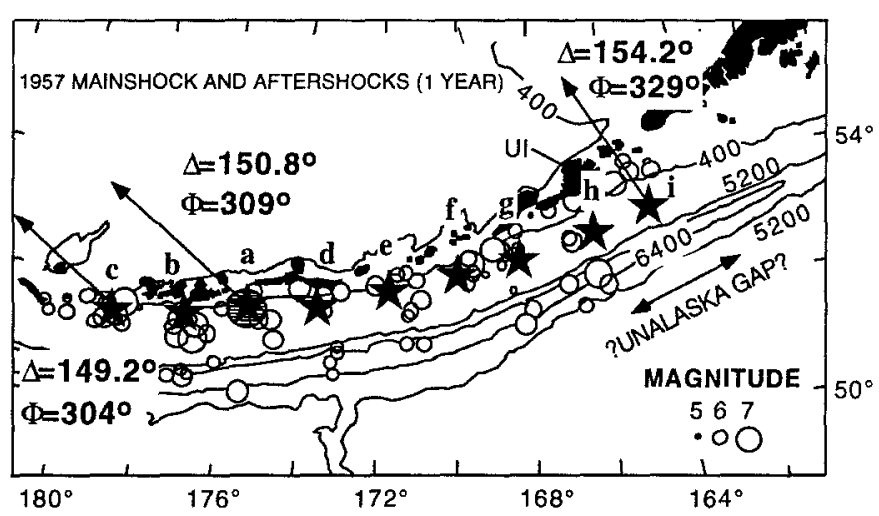

(a)

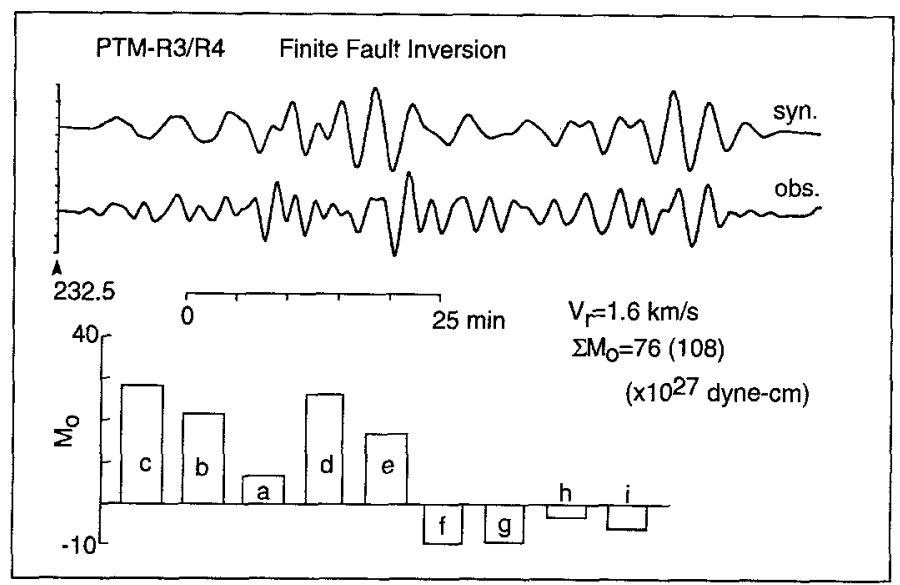

(b)

Figure 5

(a) Locations of point sources used by RUFF et al. (1985) overlaid on the aftershock distribution from House et al. (1981). Each point source has dip $20^{\circ}$ and slip direction $N 40^{\circ} \mathrm{W}$. The strike changes from $245^{\circ}$ in the east to $270^{\circ}$ in the west. (b) Moment distribution for the 1957 Aleutian earthquake estimated by Ruff et al. from the PTM record. The labeled grid points in the lower figure correspond to those in the upper map. The arrow head gives the start time of the seismograms from the origin time of the earthquake in minutes. Total moment estimate excluding negative values given in parentheses.

at zero frequency. The observed waveform is a linear superposition of the Green's functions, so the moment of each subevent can be determined by solving the linear equation

$$
A_{i j} \cdot x_{j}=b_{i}
$$

where $A_{i j}$ is the computed Green's function at station PTM for unit moment of subevent $j, b_{i}$ is the observation at PTM, and $x_{j}$ is the unknown moment of 

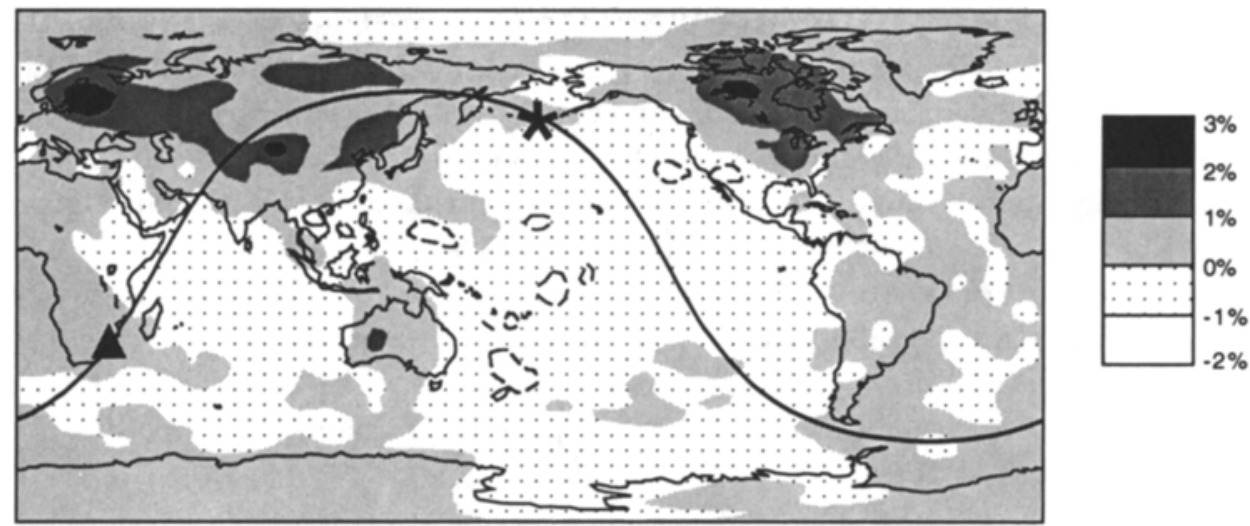

Figure 6

The great circle path connecting the 1957 earthquake (asterisk) and the South African station PTM (triangle), overlaid on the $150 \mathrm{~s}$ Rayleigh wave velocity distribution (ZHANG and TANIMOTO, 1993) in percent difference from homogeneous earth model.

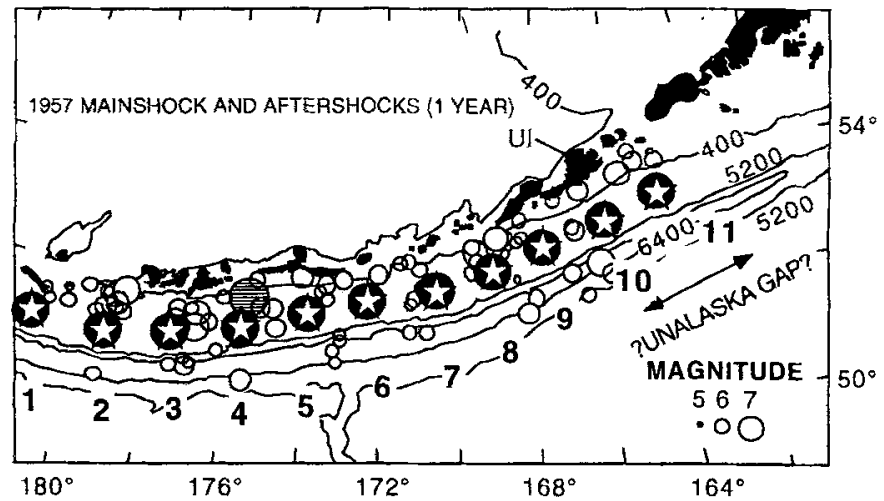

Figure 7

Location of point sources used in this study for inversion of surface wave at PTM overlaid on the aftershock distribution from House et al. (1981).

subevent $j$. This equation can be solved by a least-squares method minimizing the misfit between the observed and synthetic waveforms.

We performed 16 inversions for the spatial distribution of moment release using rupture velocities between 1.0 and $4.0 \mathrm{~km} / \mathrm{s}$ at $0.2 \mathrm{~km} / \mathrm{s}$ intervals. We also examined the effects of lateral heterogeneities, comparing both the results using the homogeneous earth model 1066A (GILBERT and DZIEWONSKI, 1975) and the laterally heterogeneous earth model of ZHANG and TANIMOTO (1993).

To create Green's functions for a laterally heterogeneous earth, we applied time corrections due to the velocity variations along the great circle path to the 
fundamental modes at each frequency (WOODHOUSE and DZIEWONSKI, 1984), then summed both the fundamental and higher modes. In detail, we first calculated the average velocity over the great circle path connecting the epicenter and the station. Next we determined the average velocity for the odd and even paths. The difference between the average velocity for the $\mathrm{R} 3$ and $\mathrm{R} 4$ paths and that of the entire great circle path is very small, with resulting time shifts of 5 seconds maximum. We could therefore ignore velocity variations due to the different velocity structures along the R3 and R4 paths and apply time shifts using the average great circle velocity. The lateral heterogeneity produced a maximum time shift for the great circle path of $40 \mathrm{~s}$ from the homogeneous earth model at periods of about $130 \mathrm{~s}$. We did not apply corrections to the higher modes.

Some of the results of 32 inversions for the moment distribution can be found in Figure 8. We also applied a positivity constraint to eliminate negative moment values. These inversion results are similar to the results using standard least squares, though the negative values become zero and the positive values are adjusted slightly. All these results vary greatly with rupture velocity, but several features are similar throughout. As with the previous results of Ruff et al., the greatest moment release occurs in the western half of the aftershock zone, although which point source has the largest moment is a function of the rupture velocity. Also, once again, the results consistently show little or no moment release in the eastern half
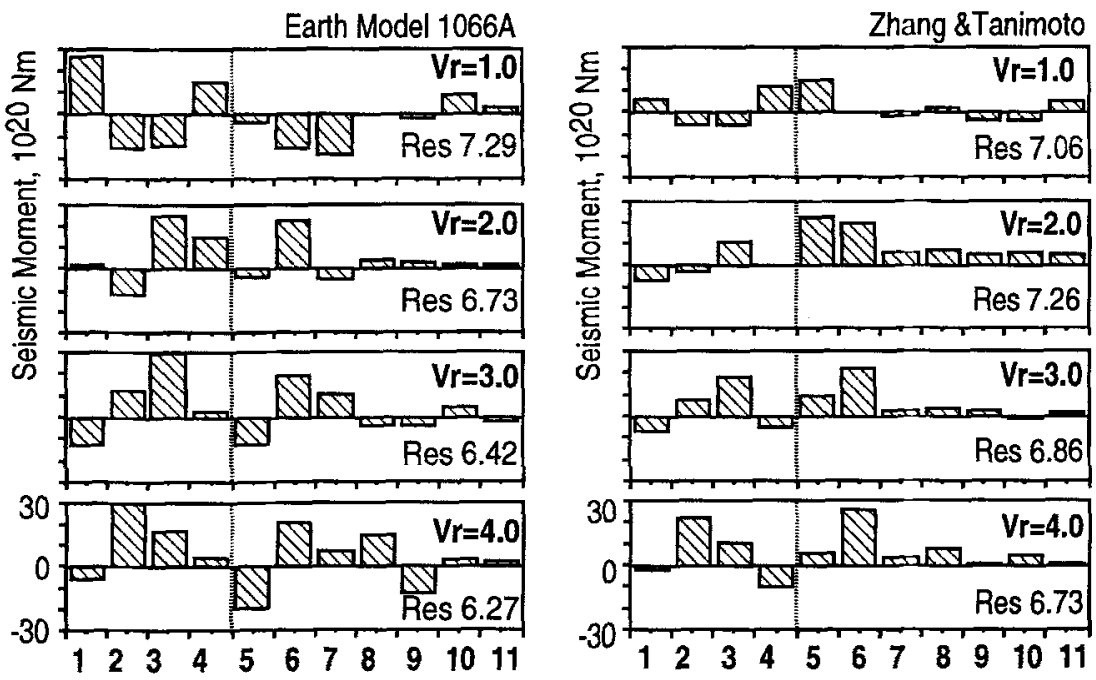

Figure 8

Moment distribution for the 1957 Aleutian earthquake using (left) the homogeneous earth model 1066A (GILBERT and DZIEWONSKI, 1975), and (right) the laterally heterogeneous earth model (ZHANG and TANIMOTo, 1993). $V_{r}$ is the rupture velocity in $\mathrm{km} / \mathrm{s}$, Res is the residual $\left(\times 10^{-4}\right) \mathrm{in} \mathrm{m}$. The dashed line between subevents 4 and 5 marks the location of the epicenter. 
of the aftershock zone. This is consistent with the suggestion of HouSE et al. (1981) that the eastern end of the aftershock zone did not rupture in the 1957 event.

Despite the consistency of results, several problems remain in our analysis of the PTM surface wave record. First, we have not been able to determine the optimum rupture velocity. There is very little difference in the fit of the synthetic waveform to the observed as measured by the residuals. In fact, the smallest residuals occur with the most extreme rupture velocities $(4.0 \mathrm{~km} / \mathrm{s})$. Figure 9 shows the observed and synthetic waveform for a typical rupture velocity of $3.0 \mathrm{~km} / \mathrm{s}$. Clearly, the best-fitting model only approximates the amplitude and waveform of the observed.

Another problem that remains concerns the response of the PTM instrument. Though the magnification was determined empirically, work of SCHWARTz and RUFF (1987) suggests that the moment of the 1958 Kurile Islands earthquake is not known precisely enough to be the sole calibration source of the PTM instrument. Also, there is a possibility that the PTM instrument characteristics changed between the 1957 and 1958 earthquakes. This makes the results from the surface wave analysis suspect, but only as regards the absolute moment release, not the spatial distribution.

We cannot determine the optimum rupture velocity, yet we still wish to ascertain if any features of the moment release distributions we obtained are consistently present, as well as determine their scatter about the mean values for each subevent. To do so, we generate from our results a "global model average" of the slip distribution, applying all the results for the 32 inversions. This "average" slip distribution is shown in Figure 10, along with one standard deviation. This may be

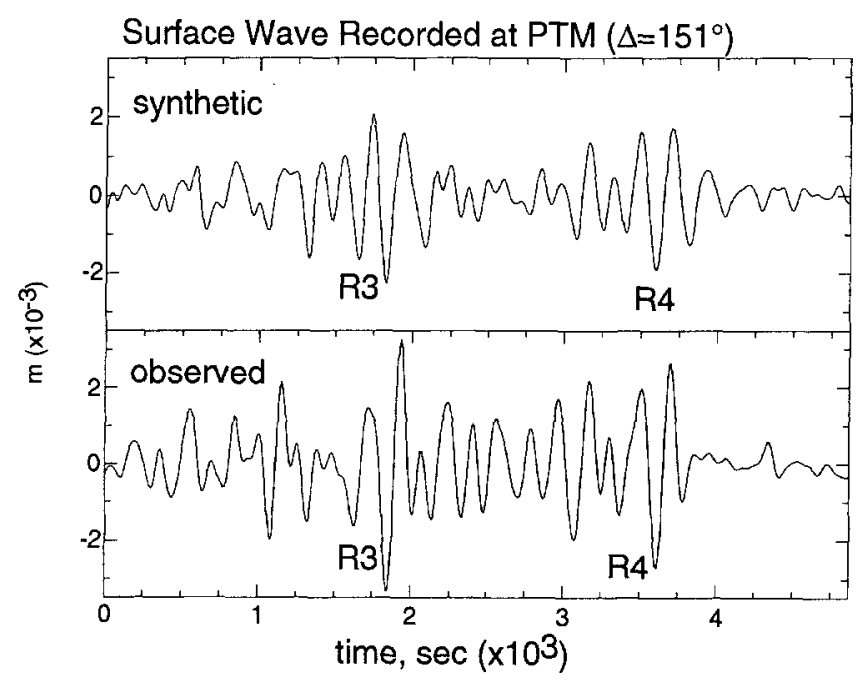

Figure 9

Synthetic (upper) and observed (lower) R3-R4 waves recorded at PTM. 


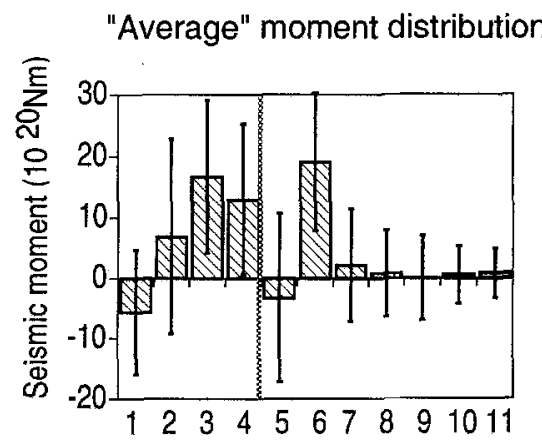

Figure 10

"Global model average" derived from 32 inversions for the slip distribution from the PTM record. The error bars denote one standard deviation.

the best estimate that can be obtained using the PTM surface wave record. The errors are large and are significantly nonzero for only two point sources. But again, the same general trend is readily apparent - large moment release in the western half of the aftershock zone, low moment release in the eastern half. The moment estimated from our surface wave analysis is $50.4 \times 10^{20} \mathrm{Nm}$.

The final consideration must be to ask how reliable is the analysis of a single surface wave record? Unfortunately, our conclusion is that only gross features of the slip distribution for the 1957 earthquake can be obtained from the PTM record. This leaves the actual slip distribution and seismic moment still poorly determined. Yet it is still vital to determine the unknown parameters if we wish to understand this earthquake and its relation to the 1986 earthquake.

\section{Tsunami Wave Studies}

Besides seismic waves, the 1957 earthquake generated a large tsunami, which was recorded on tide gauges all around the Pacific Ocean. The tsunami waveforms can be used to determine the source parameters of the 1957 earthquake. ABE (1979) previously estimated the magnitude of this earthquake from the maximum observed tsunami heights at tide gauges as $M_{t}=9.0$.

\subsection{Computation of Tsunami Propagation}

A tsunami which is generated by a large earthquake and propagates across the ocean can be treated as a linear long wave because the wavelength is substantially larger than the water depth. The wave equation for the small amplitude, linear long 
wave is

$$
\nabla h^{2}=\frac{1}{c^{2}} \frac{\partial^{2} h}{\partial t^{2}}
$$

where $c=\sqrt{g d}, h$ is the height of water displaced from the equilibrium position, $g$ is the acceleration of gravity, and $d$ is water depth. Equivalently, the equation of motion and the equation of continuity are

$$
\begin{aligned}
& \frac{\partial \mathbf{Q}}{\partial t}=-g d \nabla h \\
& \frac{\partial h}{\partial t}=-\nabla \cdot \mathbf{Q}
\end{aligned}
$$

where $\mathbf{Q}$ is the flow rate vector.

Given an initial water height, the equation of motion and equation of continuity can be solved by finite-difference calculations on a staggered grid system. Using highly accurate, digital bathymetry of the Pacific Ocean, the tsunami velocity and, thus, tsunami propagation can be calculated very accurately. A synthetic waveform is computed at the location of the tide gauges where the tsunami was actually observed.

Obviously, the tsunami velocity depends only on the water depth; therefore, the synthetic waveform is very sensitive to the bathymetry. The more accurate the bathymetry, the more accurate the computation. This suggests that a fine grid system be adopted in which to calculate the tsunami propagation. However, very fine grid spacing on the entire northern Pacific Basin would be impractical due to the enormous computational effort. For the majority of the deep Pacific Ocean where the bathymetry changes slowly, the grid space need not be any finer than $5^{\prime}$ (approximately $10 \mathrm{~km}$ ). However, near coastal areas, the bathymetry changes much more rapidly. Also, islands and harbors where tide gauges are located cannot be adequately represented by a $5^{\prime}$ grid. Therefore, in coastal areas, 1' (less than $2 \mathrm{~km}$ ) grid spacing is used. Bathymetry of $1^{\prime}$ accuracy is used for the west coast of North America, the Hawaiian Islands, and around the tide gauges in Alaska.

\subsection{Tsunami Source Area}

As stated previously, the aftershock zone of the 1957 earthquake is the longest of any recorded earthquake. The eastern end of this aftershock zone has very few aftershocks, and it has been suggested that this area did not rupture in the 1957 main event. An alternative to equating the aftershock area and the rupture area is to determine the source area by tsunami data.

The tsunami source area can be located by a backward computation of the tsunami travel time from the tide gauge to the source. An initial condition is given 
at the tide gauge location. The tsunami propagation from the tide gauge is calculated for the duration of the observed tsunami travel time to that tide gauge. The location of the leading wavefront, or travel time arc, gives the origin point of the tsunami that reached that tide gauge. When many such travel-time arcs from tide gauges distributed around the earthquake are combined, they bound a region that is the source area of the tsunami. HATORI (1981) used this method to determine the source area of the 1957 earthquake (Figure 11). However, this estimate may be unreliable. Few of the available observations were used. Also, the travel-time arcs associated with both Unalaska Island and Sitka are questionable. The travel time used by Hatori for Sitka does not agree with any published travel time, nor does it agree with the apparent arrival time on the Sitka tide gauge record. Hatori's travel-time arc for Unalaska is not compatible with a backward travel time of 83 minutes from Dutch Harbor, Unalaska where the tide gauge is located. Without these two travel-time arcs, there is no constraint on the eastern end. Most significantly, Hatori drew the inverse refraction diagrams for all the travel times manually from large-scale bathymetric maps of the Pacific Ocean.

Our numerical calculation done on a fine grid of the actual Pacific Ocean bathymetry gives more reliable results. We computed travel time arcs from tide gauges in Alaska, N. America, and Hawaii. Figure 12 shows the travel-time arcs and source area. Our source area is approximately $850 \mathrm{~km}$ long, from $180^{\circ} \mathrm{E}$ to $168^{\circ} \mathrm{W}$, and does not include the eastern end of the aftershock zone. Our source area is only slightly smaller than Hatori's original estimate; however, our source area is bounded by a greater number of travel-time arcs. Though there is a large scatter in these travel-time arcs, the best estimate of the source area does not include the Unalaska Island area.

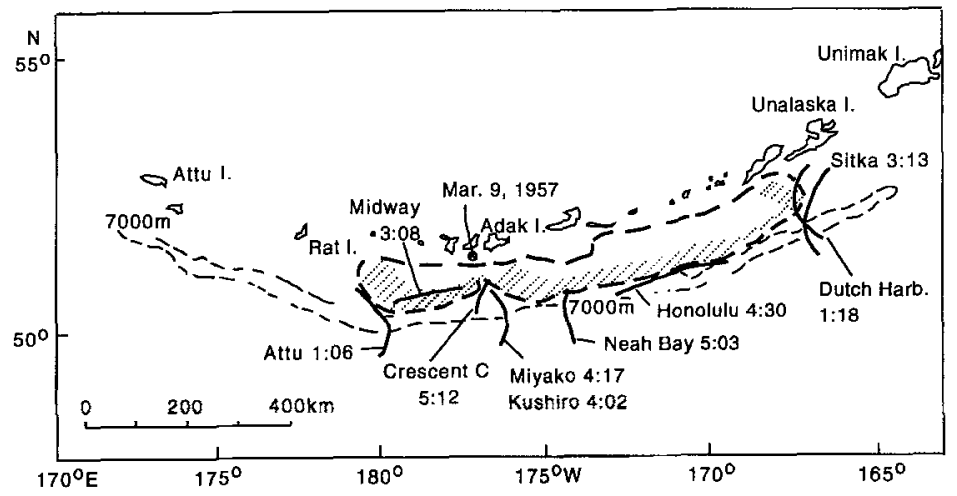

Figure 11

1957 tsunami source area derived by HATORI (1981). Travel time arcs for each tide gauge station are shown with station name and tsunami travel time in hours and minutes. Modified from HATORI (1981). 


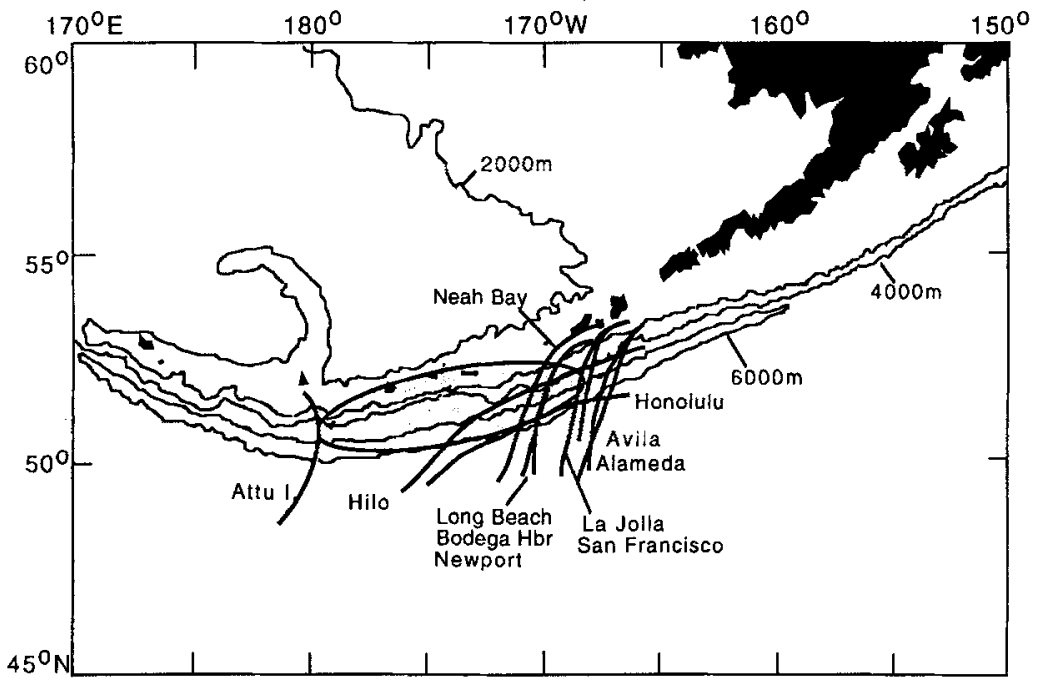

Figure 12

1957 tsunami source area (shaded) derived by backward propagation from tide gauges using finite-difference computation and digital bathymetry. Travel-time arcs for each tide gauge station are shown with station name.

Both the surface wave results and the backward computation of the tsunami support the conclusion of HOUSE et al. (1981) that the 1957 earthquake ruptured a smaller section of the arc than can be assumed from the aftershock area.

\subsection{Tsunami Waveform Inversion}

While the tsunami source area can be estimated from the tsunami travel times by backward propagation, only the extent of the source area can be estimated and no information is provided about the slip distribution. We can obtain the slip distribution, which will give an estimate of the moment, by inverting tsunami waveforms, as has been done previously by SATAKE (1989) for determining the slip distribution of the 1968 Tokachi-Oki and the 1983 Japan Sea earthquakes. Those studies used local and regional tsunami data, while this study is the first to determine slip distribution from far-field tsunami waveforms (JOHNSON and SATAKE, 1993).

\section{A. Method}

We divided the aftershock zone of the 1957 earthquake into eleven subfaults. The following fault parameters were the same for each subfault: length $100 \mathrm{~km}$, width $150 \mathrm{~km}$, dip $15^{\circ}$, and depth to the top of the subfault $1 \mathrm{~km}$. (Figure 15 shows the location of the subfaults in relation to the Aleutian Arc.) Each subfault has unit 
displacement in the direction of Pacific Plate motion relative to $\mathrm{N}$. America. The displacement direction was determined for each subfault individually from the $\mathbf{N}$. America-Pacific Euler pole at $48.7^{\circ} \mathrm{N},-78.2^{\circ} \mathrm{E}$ (DEMETs et al., 1990). This means that the slip changes from pure dip-slip in the eastern end of the rupture zone to nearly equal components of dip-slip and strike-slip in the west. The initial condition is specified by the deformation of the ocean floor due to a buried fault as given by a set of equations such as OKADA's (1985). This provides the initial condition in the source area. The tsunami waveform was then computed for each subfault and used as the Green's function. An example of the Green's functions for Attu is shown in Figure 13. The Green's functions are significantly different for each subfault, so the slip distribution can be resolved from them.

Recent studies by EKSTRÖM and ENGDAHL (1989) and MCCAFFREY (1992) show that slip vectors of other earthquakes in the central Aleutians do not conform to the slip direction as predicted by plate motions, but are closer to arc-normal. If this is the case for the 1957 event, the difference between these directions is small, approximately $15^{\circ}$. We tested whether this difference would have an effect on the Green's functions. Our test shows that the waveforms with the more arc-normal slip direction are different from the waveforms from the plate motion slip direction only in small details, and these differences do not affect our results.

Next we inverted the waveforms from 12 tide gauges from Alaska, the Aleutians, Hawaii, and N. America by again solving Equation (1). These tide gauges are

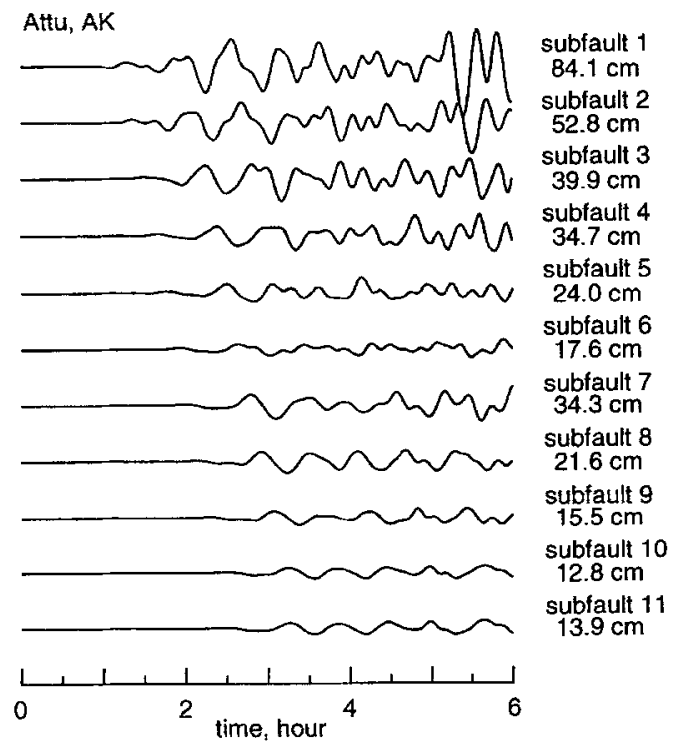

Figure 13

Synthetic tsunami waveforms from each subfault for Attu Island, AK tide gauge. Maximum peak-topeak amplitudes for each trace are shown. 
Attu, Unalaska, and Yakutat, AK; Neah Bay, WA; San Francisco, Alameda, San Pedro, Los Angeles Harbor, Newport Bay, and San Diego, CA; and Hilo, HI. The waveform data at each tide gauge station consist of an average of 110 time points with sampling interval of $1 \mathrm{~min}$ and the total number of data points is 1312. Figure 14 displays the observed and computed waveforms from these tide gauges. We performed both a standard least squares inversion and an inversion with a positivity constraint.

\section{B. Slip Distribution}

The slip distribution from the solution with a positivity constraint can be seen in Figure 15 and Table 1. It shows that the greatest slip occurred in the western half of the aftershock zone between $174^{\circ} \mathrm{W}$ and $180^{\circ} \mathrm{W}$. The greatest slip occurred on subfault $4(7 \mathrm{~m})$ and subfault $5(5 \mathrm{~m})$ between $174^{\circ}$ and $177^{\circ} \mathrm{W}$. There is very little slip in the eastern half of the aftershock zone, with subfault 8 having the only appreciable slip. There is no slip in the easternmost subfaults (aside from negligible slip on subfault 11) from $164^{\circ}$ to $169^{\circ} \mathrm{W}$, which corresponds to the results from determination of the tsunami source area. The results for both the standard and constrained solutions are compared in Table 1. The slip distributions in the western half of the rupture zone for both inversions are fairly compatible. In the eastern half, the subfaults that are given negative values in the standard inversion are almost all zero under the positivity constraint. The RMS values for both inversions are almost the same. However, in a qualitative way, the synthetic and observed waveforms match more closely in the constrained solution. In the standard leastsquares solution, arrivals are observed in the synthetic waveform prior to the time of the true first arrival in the observed waveform. In the constrained solution, the arrival times of the synthetics match the observed.

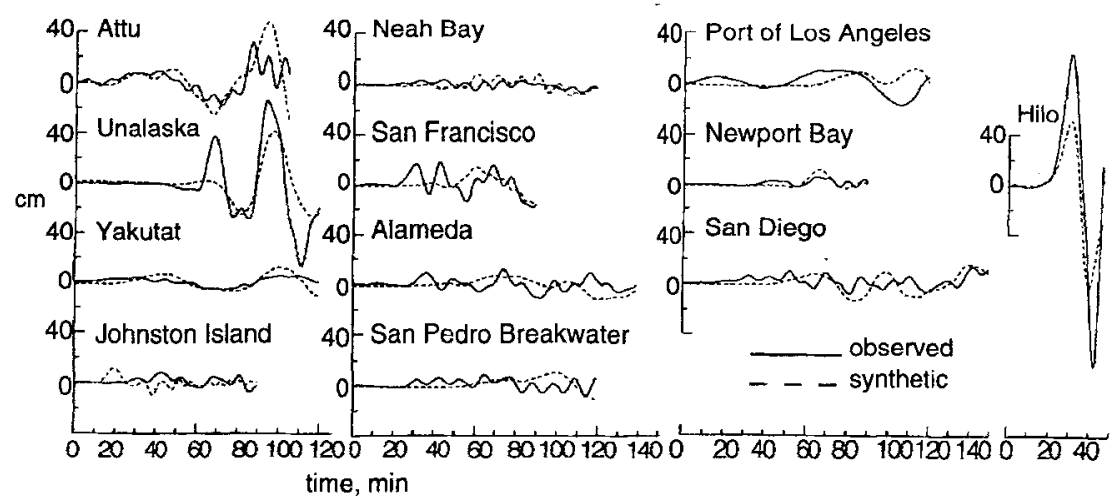

Figure 14

Observed and synthetic waveforms from nonnegative least-squares inversion for eleven subfaults. Start time of each waveform is different. 


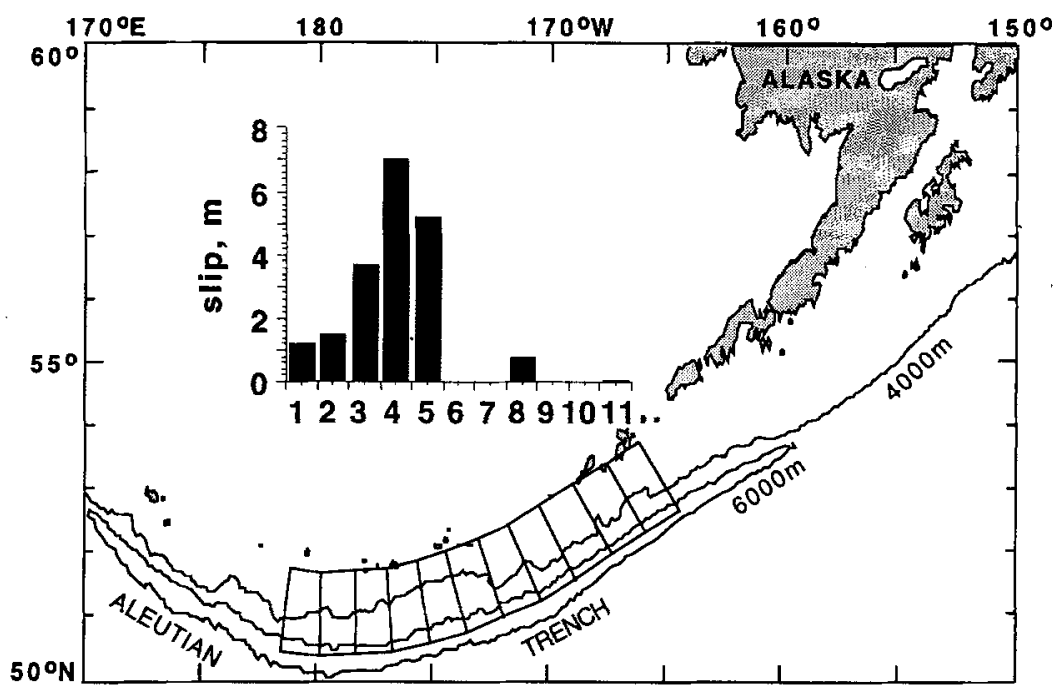

Figure 15

Slip distribution on rupture zone of 1957 earthquake from nonnegative least squares inversion for eleven subfaults. The numbered segments correspond to the subfault immediately below.

Table 1

Inversion results for 11 subfaults

\begin{tabular}{rlcccc}
\hline & \multicolumn{2}{c}{ Nonnegative LS } & & \multicolumn{2}{c}{ Standard LS } \\
\cline { 2 - 3 } \cline { 5 - 6 } Subfault \# & Slip, m & Error, $\mathrm{m}$ & & Slip, m & Error, m \\
\hline 1 & 1.1 & 0.66 & & 1.3 & 1.93 \\
2 & 1.5 & 0.51 & & 1.3 & 1.17 \\
3 & 3.7 & 1.00 & & 3.6 & 1.31 \\
4 & 7.0 & 1.07 & & 6.1 & 1.15 \\
5 & 5.2 & 0.59 & & 4.5 & 0.74 \\
6 & 0.0 & 0.00 & & -1.4 & 0.37 \\
7 & 0.0 & 0.16 & & -0.25 & 0.44 \\
8 & 0.76 & 0.32 & & 0.81 & 0.27 \\
9 & 0.0 & 0.35 & -0.45 & 0.47 \\
10 & 0.0 & 0.00 & -2.5 & 0.54 \\
11 & 0.08 & 0.27 & 2.5 & 0.53 \\
\hline
\end{tabular}

\begin{tabular}{lcc}
\hline RMS error, $\mathrm{m}$ & .1002 & .0967 \\
Average slip, $\mathrm{m}$ & 1.77 & 1.42 \\
$M_{0}, 10^{20} \mathrm{Nm}$ & 87.6 & 70.3 \\
\hline
\end{tabular}


While the computed waveforms for the constrained solution explain the overall features of the observed waveforms, a careful examination of Figure 14 reveals that the first large positive pulses at Unalaska and San Francisco are, among others, poorly matched. Though not shown, the same is true for the standard least-squares inversion results. A larger displacement on subfault 8 can explain the first pulse at Unalaska, and a large displacement on subfault 9 can explain the first pulse at San Francisco. However, large displacements in either of these subfaults are incompatible with the large amplitude wave at Hilo. We hypothesized from an examination of first arrival times at the three tide gauges in question, that a large displacement on a subfault of smaller area and at the down-dip edge of subfaults 8 or 9 might be compatible with all three waveforms. Accordingly, we divided subfaults 8 and 9 into smaller faults. Figure 16 shows the position of the additional subfaults 12 and 13. These subfaults have parameters: length $50 \mathrm{~km}$, width $75 \mathrm{~km}$, dip $15^{\circ}$, and depth to the top of fault $20.4 \mathrm{~km}$. Green's functions were computed for these additional faults, and the inversion was performed again. Figure 17 shows that a displacement of $3.3 \mathrm{~m}$ on subfault 12 improves the match of the first pulse on the Unalaska waveform and is still compatible with the Hilo waveform. However, the first pulse on the San Francisco waveform is still poorly matched. The slip distribution results are shown in Figure 16 and Table 2. The solution for 13 subfaults is compatible with our hypothesis of concentration of slip on a smaller subfault in the eastern half of the rupture zone. It is also compatible with the total average slip for the entire rupture zone, as the slip on subfault 12 is approximately four times the slip on

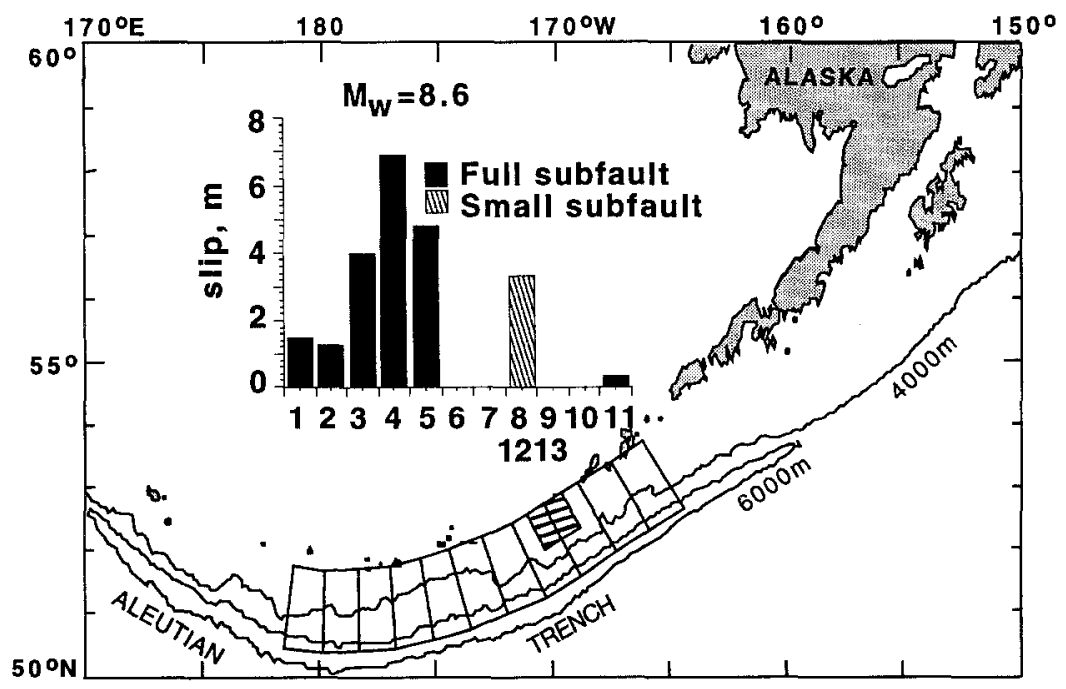

Figure 16

Slip distribution on rupture zone of 1957 earthquake from nonnegative least-squares inversion for thirteen subfaults. The numbered segments correspond to the subfault immediately below. The subfaults corresponding to 12 and 13 are shaded. 


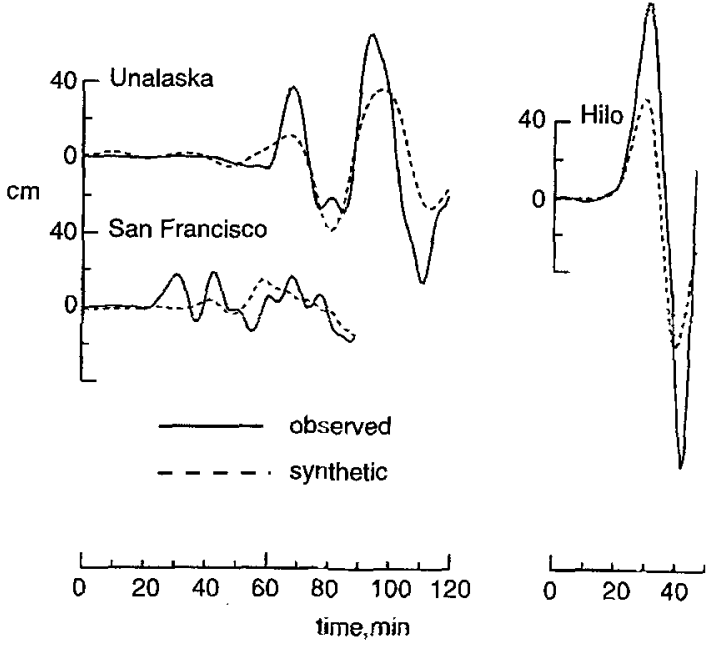

Figure 17

Observed and synthetic waveforms from nonnegative least-squares inversion for thirteen subfaults. Start time of each waveform is different. Not all waveforms used in inversion are shown.

Table 2

Inversion results for 13 subfaults

\begin{tabular}{|c|c|c|c|c|}
\hline \multirow[b]{2}{*}{ Subfault \# } & \multicolumn{2}{|c|}{ Nonnegative LS } & \multicolumn{2}{|c|}{ Standard LS } \\
\hline & Slip, m & Error, m & Slip, m & Error, $m$ \\
\hline 1 & 1.5 & 0.74 & 1.7 & 1.77 \\
\hline 2 & 1.3 & 0.46 & 0.99 & 1.30 \\
\hline 3 & 4.0 & 3.04 & 4.0 & 0.53 \\
\hline 4 & 6.9 & {$[.10$} & 6.0 & 1,01 \\
\hline 5 & 4.8 & 0.56 & 3.6 & 0.65 \\
\hline 6 & 0.0 & 0.00 & -1.4 & 0.43 \\
\hline 7 & 0.0 & 0.01 & -0.12 & 0.37 \\
\hline 8 & 0.0 & 0.13 & -0.30 & 0.75 \\
\hline 9 & 0.0 & 0.32 & -0.55 & 0.46 \\
\hline 10 & 0.0 & 0.00 & -2.8 & 1.76 \\
\hline 11 & 0.32 & 0.27 & 3.0 & 1.67 \\
\hline 12 & 3.3 & 0.26 & 5.1 & 0.64 \\
\hline 13 & 0.0 & 0.03 & -1.6 & 1.49 \\
\hline RMS error, m & & & & .0925 \\
\hline Average slip, m & & & & 1.36 \\
\hline$M_{0}, 10^{20} \mathrm{Nm}$ & & & & 67.3 \\
\hline
\end{tabular}


subfault 8 from the solution for eleven subfaults. However, the San Francisco record indicates that there may be more slip in the eastern half of the aftershock zone that we cannot resolve.

\section{Error Estimates}

The formal statistical errors for a standard least-squares inversion cannot always be considered a good estimate of the actual errors (TICHELAAR and RUFF, 1989). Further no formal errors can be estimated for a nonnegative least-squares inversion. Therefore, we applied a resampling technique to determine the errors. We reinverted the tsunami waveforms twelve times, each time dropping one waveform from each of the tide gauge stations from the data. This gives twelve estimates of the slip distribution, and a mean and standard deviation for the slip on each subfault can be determined.

This technique for determining the errors is similar to the jackknifing technique described by TICHELAAR and RUFF (1989). In jackknifing, a fixed number of random data points are deleted to produce a resample that is then inverted for the model parameters. If we treat each waveform as 110 data points out of a total of 1312 data points, then we must consider our resample as a delete- 110 jackknife with corresponding errors. These errors are simply the standard errors multiplied by a scale factor. In our case the scale factor is approximately three.

Our original error estimates for the slip distribution using this method were sizable, but still retained the major features discussed. However, since we delete an entire waveform at a time, rather than 110 random data points, the errors determined can be strongly influenced by the presence or absence of certain waveforms. Therefore, we examined each of the jackknife inversions and determined that two waveforms, Hilo and Attu, were necessary to obtain a stable solution. We recomputed the errors using only those jackknives which included both Hilo and Attu. These errors are given in Tables 1 and 2. These error estimates show that the slip distribution is significantly nonzero except for: subfaults 1 and 8 in the inversion for 11 subfaults, and subfault 1 in the inversion for 13 subfaults. These error estimates show that the concentration of slip in the western half of the aftershock zone and the small slip in the eastern half are real.

\section{Comparison of Seismic and Tsunami Results}

As stated in the introduction, estimates of the seismic moment release of the 1957 earthquake, based on the size of the aftershock zone, vary by as much as an order of magnitude. However, the aftershock zone is an indirect means of deriving the moment. With slip distribution as determined by surface waves and especially tsunami waves, the seismic moment can now be more accurately estimated. The estimate from the constrained inversion of tsunami waveforms is $88 \times 10^{20} \mathrm{Nm}$. 
Table 3

Ten largest earthquakes of 20th century (Modified from KANAMORI, 1977)

\begin{tabular}{lll}
\hline Event & Year & $M_{w}$ \\
\hline Chile & 1960 & 9.5 \\
Alaska & 1964 & 9.2 \\
Kamchatka & 1952 & 9.0 \\
Ecuador & 1906 & 8.8 \\
Aleutian & 1965 & 8.7 \\
Assam & 1950 & $8.6^{*}$ \\
Aleutian & 1957 & 8.6 \\
Kurile Islands & 1963 & 8.5 \\
Chile & 1922 & 8.5 \\
Banda Sea & 1938 & 8.5 \\
\hline
\end{tabular}

* Estimated moment of 1950 Assam earthquake is $100 \times 10^{20} \mathrm{Nm}$.

This estimate gives a moment magnitude of $M_{w}=8.6$. This is much smaller than the estimate of $M_{w}=9.1$ originally assigned by KANAMORI (1977). However, this estimate is in good agreement with the estimate of $100 \times 10^{20} \mathrm{Nm}$ by RUFF et al. (1985) and with our estimate of $50.4 \times 10^{20} \mathrm{Nm}$ from surface wave analysis. The slip distribution determined from tsunami inversion also agrees in a qualitative way with the surface wave analysis; namely, that slip was concentrated in the western half of the aftershock zone. The tsunami results show the highest slip in the area of the epicenter, while the surface wave analysis shows that the greatest slip occurred farther away from the epicenter. However, it must be recalled that the surface wave results were inconclusive. The tsunami results were obtained from a larger and more reliable data set. It should be noted, however, that BoYD et al. (1992) have speculated from the aftershock sequence that moment release was concentrated in the eastern section of the aftershock zone from $167^{\circ}$ to $175^{\circ} \mathrm{W}$ rather than in the western section. To conclude, our best estimate of the seismic moment is $88 \times 10^{20} \mathrm{Nm}$, which "demotes" the 1957 Aleutian earthquake to the seventh largest event of this century (Table 3).

\section{The 1986 Andreanof Islands Earthquake}

We can examine the 7 May 1986 Andreanof Islands earthquake in the light of the new results we have obtained for the 1957 earthquake.

As noted, the epicenters for these two events are nearly coincident. Both earthquakes ruptured bilaterally from the epicenter. Although there is some dis- 
agreement between various researchers about the spatial distribution of moment release for the 1986 earthquake (see references cited in section on body waves), it is clear that the aftershock zone in this case coincides with the area of significant moment release. We can compare this to the area of significant moment release for the 1957 earthquake as determined by tsunami waveform inversion. The 1986 earthquake occurred almost entirely within the area of significant moment release of the 1957 earthquake (Figure 18). A small portion of the major rupture of the 1986 earthquake lies to the east of the major rupture area of the 1957 earthquake, but clearly, the 1986 earthquake is not filling in areas of low moment release from the 1957 earthquake, but is a major rerupturing of this segment of the arc.

This leads us to reconsider the seismic potential of the rest of the 1957 rupture area. The entire area may have a low potential for an earthquake of the same magnitude as the 1957 event, but a high potential for earthquakes of the same magnitude as the 1986 event. To look at the historic record, the central Aleutians ruptured in a number of large earthquakes $(M \sim 7.5)$ around the turn of the century (SYKes et al., 1981). Though little is known about these earthquakes (i.e., rupture length, moment), they apparently ruptured several segments of the 1957 rupture zone. Taking these turn-of-the-century earthquakes and the better-understood 1957 and 1986 events, we can theorize that the central Aleutians may display a bimodal rupture process. Great earthquakes with large rupture areas may be followed by several smaller earthquakes that break segments of the larger earthquake's rupture area. The 1957-1986 sequence may be similar to the history of subduction earthquakes in Colombia where the 1906 earthquake ruptured a large area and was followed by the 1942, 1958, and 1979 earthquakes (see Figure 19), which successively reruptured the entire 1906 area (KELLEHER, 1972; KANAMORI and MCNALLY, 1982). If this is the case, the central Aleutians, particularly the

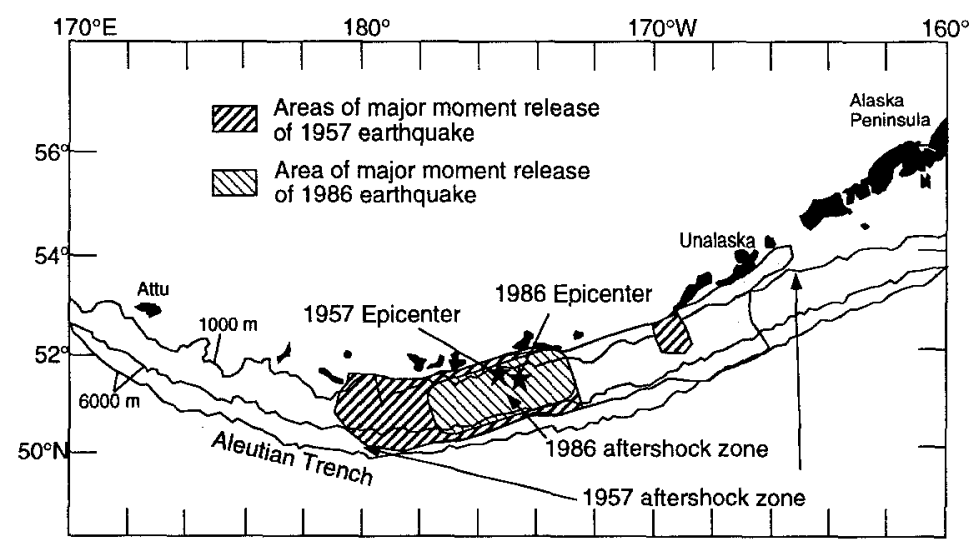

Figure 18

Areas of major moment release of 1957 Aleutian and 1986 Andreanof Islands earthquakes. 


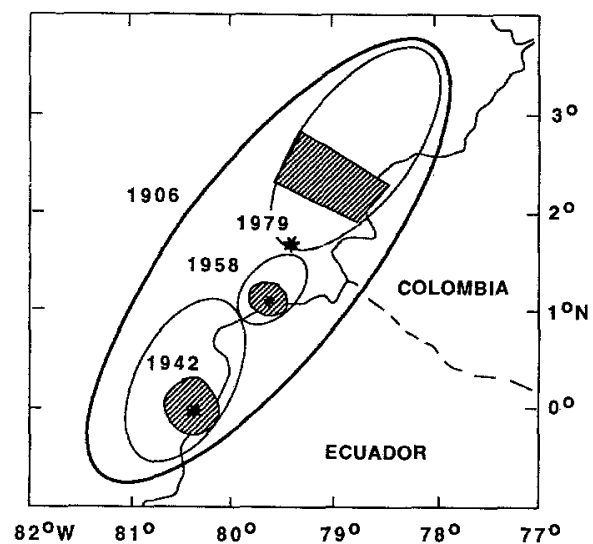

Figure 19

Rupture zones of earthquakes in Colombia-Ecuador subduction zone. Stars denote epicenters. Shaded areas represent asperities. Modified from BECK and RUFF (1987).

western end of the aftershock zone, may have high risk for earthquakes with $M \sim 7-8$ in the future. Our results support this possibility, which is reflected in the latest seismic potential maps of the central Aleutian Islands (NISHENKO, 1991).

Further questions are also raised by our results, which show that low moment release occurred in the eastern half of the 1957 aftershock zone, as well as confirm the existence of the Unalaska Gap. Do these areas have a high seismic potential? Or does the low moment release indicate that convergence in this area has a large aseismic component? Of particular interest is the Unalaska Gap, as no great earthquakes have ever been unambiguously identified as having occurred there. Future research must answer these questions in order to fully assess the seismic potential and seismic and tsunami hazards in the central Aleutians.

\section{Acknowledgments}

We wish to thank two anonymous reviewers whose comments helped improve our manuscript. This work was supported by the U.S. Geological Survey (143492-G-2187 and 1434-93-G-2320) and the National Science Foundation (EAR$90-19003)$. This work was partially supported by NSF grant EAR920000N and utilized the Cray- 2 system at the National Center for Supercomputing Applications, University of Illinois at Urbana-Champaign. J. M. J. was partially supported by a Shell Graduate Grant. 


\section{REFERENCES}

ABE, K. (1979), Size of Great Earthquakes of 1873-1974 Inferred from Tsunami Data, J. Geophys. Res. $84,1561-1568$.

BeCK, S., and RUfF, L. (1987), Rupture Process of the Great 1963 Kurile Islands Earthquake Sequence: Asperity Interaction and Multiple Event Rupture, J. Geophys. Res. 92, 14123-14138.

Boyd, T. M., Engdahl, E. R., and SPence, W., Analysis of seismicity associated with a complete seismic cycle along the Aleutian arc: 1957-1979. In Wadati Conference on Great Subduction Earthquakes, Sept. 16-19, 1992 (eds. Christensen, D., Wyss, M., Habermann, R. E., and Davies, J.) 43-50 in extended abstracts, 1992.

BoYd, T. M., and NÁBÊLEK, J. L. (1988), Rupture Process of the Andreanof Islands Earthquake of May 7, 1986, Bull. Seismol. Soc. Am. 78, 1653-1673.

Das, S., and Kostrov, B. V. (1990), Inversion for Seismic Slip Rate History and Distribution with Stabilizing Constraints: Application to the 1986 Andreanof Islands Earthquake, J. Geophys. Res. 95, 6899-6913.

DeMets, C., Gordon, R. G., Argus, D. F., and Stein, S. (1990), Current Plate Motions, Geophys. J. Int. 101, 425-478.

EkströM, G., and ENGDAhL, E. R. (1989), Earthquake Source Parameters and Stress Distribution in the Adak Island Region of the Central Aleutian Islands, Alaska, J. Geophys. Res. 94, 15499-15519.

Fukao, Y., and Furumoto, M. (1979), Stress Drops, Wave Spectra and Recurrence Intervals of Great Earthquakes -Implications of the Etorofu Earthquake of 1958 November 6, Geophys. J. R. Astr. Soc. $57,23-40$.

Gilbert, F., and Dziewonski, A. M. (1975), An Application of Normal Mode Theory to the Retrieval of Structural Parameters and Source Mechanisms from Seismic Spectra, Philos. Trans. R. Soc. London, Ser. A $278,187-269$.

HAtori, T. (1981), Tsunami Magnitude and Source Area of the Aleutian-Alaska Tsunamis, Bull. Earthq. Res. Inst., Univ. of Tokyo 56, 97-110.

House, L. S., Sykes, L. R., DAvies, J. N., and JACOB, K. H., Identification of a possible seismic gap near Unalaska Island, eastern Aleutians, Alaska. In Earthquake Prediction-An International Review (eds. Simpson, D. W., and Richards, P. G.) 81-92 (American Geophysical Union, 1981).

Houston, H., and Engdahl, E. R. (1989), A Comparison of the Spatio-temporal Distribution of Moment Release for the 1986 Andreanof Islands Earthquake with Relocated Seismicity, Geophys. Res. Lett. $16,1421-1424$.

HWANG, L. J., and KANAmori, H. (1986), Of the May 7, 1986 Andreanof Islands Earthquake Source Parameters, Geophys. Res. Lett. 13, 1426-1429.

Johnson, J. M., and SATAKe, K. (1993), Source Parameters of the 1957 Aleutian Earthquake from Tsunami Waveforms, Geophys. Res. Lett. 20, 1487-1490.

Kanamori, H. (1977), The Energy Release in Great Earthquakes, J. Geophys. Res. 82, 2981-2987.

KANAMORI, H., and MCNALly, K. C. (1982), Variable Rupture Mode of the Subduction Zone along the Ecuador-Colombia Coast, Bull. Seismol. Soc. Am. 72, 1241-1253.

Kelleher, J. A. (1972), Rupture Zones of Large South American Earthquakes and Some Predictions, J. Geophys. Res. 77, 2087-2103.

LANE, F. D., and Boyd, T. M. (1990), A Simulated Annealing Approach to the Inversion of Surface Wave Directivities, EOS 71, 1468.

MCCAFFreY, R. (1992), Oblique Plate Convergence, Slip Vectors, and Forearc Deformation, J. Geophys. Res. 97, 8905-8915.

Nishenko, S. P. (1991), Circum-Pacific Seismic Potential: 1989-1999, Pure and Appl. Geophys. 135, $169-259$.

Nishenko, S. P., and MCCANn, W. R., Seismic potential for the world's major plate boundaries: 1981. In Earthquake Prediction - An International Review (eds. Simpson, D. W., and Richards, P. G.) 20-28 (American Geophysical Union, 1981).

OKadA, Y. (1985), Surface Deformation due to Shear and Tensile Faults in a Half-space, Bull. Seismol. Soc. Am. 75, 1135-1154. 
Ruff, L., and Kanamori, H. (1983), The Rupture Process and Asperity Distribution of Three Great Earthquakes from Long-period Diffracted $P$ Waves, Phys. Earth Planet. Inter. 31, 202-230.

RufF, L., KANAMORI, H., and SYKeS, L. R. (1985), The 1957 Great Aleutian Earthquake, EOS 66, 298.

SATAKE, K. (1989), Inversion of Tsunami Waveforms for the Estimation of Heterogeneous Fault Motion of Large Submarine Earthquakes: The 1968 Tokachi-oki and the 1983 Japan Sea Earthquakes, J. Geophys. Res. 94, 5627-5636.

SCHWARTz, S. Y., and RUFF, L. J. (1987), Asperity Distribution and Earthquake Occurrence in the Southern Kuril Islands Arc, Phys. Earth Planet. Inter. 49, 54-77.

SYKes, L. (1971), Aftershock Zones of Great Earthquakes, Seismicity Gaps, and Earthquake Prediction for Alaska and the Aleutians, J. Geophys. Res. 76, 8021-8041.

SyKes, L. R., Kisslinger, J. B., House, H., Davies, J. N., and JACOB, K. H., Rupture zones and repeat times of great earthquakes along the Alaska-Aleutian Arc, 1784-1980. In Earthquake Prediction-An International Review (eds. Simpson, D. W., and Richards, P. G.) 73-80 (American Geophysical Union, 1981).

TiCheLAAR, B. W., and RUFF, L. J. (1989), How Good are our Best Models? Jackknifing, Bootstrapping, and Earthquake Depth, EOS 70, 593, 605-606.

Woodhouse, J. H., and DzIEWONSK1, A. M. (1984), Mapping the Upper Mantle: Three-dimensional Modeling of Earth Structure by Inversion of Seismic Waveforms, J. Geophys. Res. 89, 5953-5986.

YoshidA, S. (1992), Waveform Inversion for Rupture Process using a Non-flat Seafloor Model: Application to 1986 Andreanof Islands and 1985 Chile Earthquakes, Tectonophys. 211, 45-59.

ZhANG, Y.-S., and TANimoto, T. (1993), High-resolution Global Upper Mantle Structure and Plate Tectonics, J. Geophys. Res. 98, 9793-9823.

(Received April 6, 1993, revised September 18, 1993, accepted October 2, 1993) 